\title{
UNIDADES PEDOAMBIENTAIS DA REGIÃO DE SANTA TEREZA, ESTADO DO TOCANTINS ${ }^{1}$
}

\author{
Helena Maria de Paula Santana'2 , Marilusa Pinto Coelho Lacerda ${ }^{3}$, \\ Marco Aurélio Barros ${ }^{4}$, Inara Oliveira Barbosa ${ }^{5}$
}

\begin{abstract}
PEDOENVIRONMENTAL UNITS OF THE SANTA

TEREZA REGION, TOCANTINS STATE, BRAZIL

A sustainable environmental management, through a joint vision of natural resources, has been adopted for monitoring land sustainability, particularly those with agricultural use. This work aimed the characterization and definition of pedoenvironmental units, to provide subsidies to the development of sustainable land use plans, through the characterization of the main soil classes found in the Santa Tereza region, Tocantins State, Brazil, and their relations with the relief, geology, agriculture suitability, and land use and occupation, with the use of geoprocessing techniques. In the area of study, a pedological transect, with characterization of seven soil representative profiles, was conducted. The soils were classified as Dystrophic Rhodustox, Distrophic Plintustox, Distrophic Haplustox, Distrophic Haplustept, Typic Troppsamment, and Distrophic Tropsaprent, and over $63.5 \%$ of the total area was covered with native vegetation. According to the agricultural suitability evaluation, lands were classified as 2(b)c, 4p, 4(p), 5(n), and 6, and four pedoenvironmental units were individualized: Rhodustox domain, Plintustox domain, Rocks domain + Haplustept, and Quartzipsamment domain + Tropsaprent.
\end{abstract}

KEY-WORDS: Tocantins State soils; agricultural suitability; pedoenvironment; environmental sustainability.

\section{INTRODUÇÃO}

A gestão territorial e ambiental necessitam de conhecimento prévio, à respeito da região foco, sobretudo de seus recursos naturais, visto que as tomadas de decisão podem ter efeitos variáveis na sustentabilidade ambiental.

O planejamento, como ferramenta de gerenciamento racional de recursos naturais e atividades

\section{RESUMO}

A gestão ambiental sustentável, mediante visão conjunta de recursos naturais, vem sendo adotada para o monitoramento da sustentabilidade do uso de terras, particularmente aquelas de uso agropecuário. Este trabalho teve como objetivo a caracterização e delimitação de unidades pedoambientais, a fim de fornecer subsídios para a elaboração de planejamentos de usos racionais de terras, por meio da caracterização das principais classes de solos da região de Santa Tereza (TO) e suas relações com o relevo, geologia, aptidão agrícola e uso e cobertura das terras, com o auxílio de técnicas de geoprocessamento. $\mathrm{Na}$ área do estudo, foi estabelecido um transecto pedológico, onde foram caracterizados sete perfis pedológicos de representatividade regional. Os solos foram classificados como Latossolo Vermelho e VermelhoAmarelo, Plintossolo Pétrico, Cambissolo Háplico, Neossolo Quartzarênico e Regolítico. Constatou-se que cerca de 63,5\% da área encontra-se com cobertura vegetal nativa. A avaliação da aptidão agrícola das terras permitiu a classificação em 2(b)c, $4 p, 4(p), 5(n)$ e 6 . Com os dados obtidos, foram caracterizadas e individualizadas quatro unidades pedoambientais: domínio dos Latossolos, domínio dos Plintossolos, domínio dos Neossolos Litólicos + Cambissolos e domínio dos Neossolos Quartzarênicos + Neossolos Regolíticos.

PALAVRAS-CHAVE: Solos do Estado do Tocantins; aptidão agrícola; unidades pedoambientais; sustentabilidade ambiental.

econômicas, utiliza técnicas, instrumentos e metodologias para prever situações futuras e permite ordenar as atividades ao longo do tempo. No planejamento rural, que visa ao desenvolvimento de uma produção agropecuária sustentável, a preservação de recursos naturais é preconizada. Para a gestão racional dos recursos naturais, são necessários conhecimentos sobre os solos, hidrologia, correntes de ar, vegetação e fauna, considerando-se suas inter-relações (Brasil 2000).

1. Trabalho recebido em abr./2008 e aceito para publicação em fev./2010 (nº registro: PAT 3839/ DOI: 10.5216/pat.v40i1.3839).

2. Instituto Natureza do Tocantins (Naturatins), Coordenadoria de Monitoramento Florestal, Palmas, TO, Brasil. E-mail: helenasantana@uol.com.br.

3. Universidade de Brasília (UnB), Faculdade de Agronomia e Medicina Veterinária, Departamento de Solos e Geoprocessamento, Brasília, DF, Brasil.E-mail: marilusa@unb.br.

4. Geoambiente, Departamento de Sensoriamento Remoto, São José dos Campos, SP, Brasil. E-mail: maaubar@yahoo.com.br. 5. Universidade de Brasília (UnB), Faculdade de Agronomia e Medicina Veterinária, Laboratório de Geoprocessamento, Brasília, DF, Brasil.E-mail: inarabar@yahoo.com.br. 
O Sistema de Avaliação da Aptidão Agrícola de Terras é um instrumento utilizado na predição do comportamento de terras, sendo útil para a elaboração do planejamento de uso agrícola do solo, de forma conservacionista (Ramalho Filho \& Beek 1995). Para o estabelecimento de técnicas de manejo agrícola, que permitam a utilização dos solos, sem degradá-los, é necessário, portanto, conhecer os atributos físicos e químicos dos solos (Jorge 1986).

As geotecnologias, representadas pelos Sistemas de Informações Geográficas (SIGs) e Sensoriamento Remoto, segundo Alvarenga et al. (2003), vêm se constituindo em tecnologias importantes para o planejamento, uso e monitoramento dos recursos naturais terrestres e vêm sendo adotadas como ferramentas para a gestão ambiental e na execução de políticas públicas, nos âmbitos federal, estadual e municipal.

Estudos de compartimentação da paisagem, agregando informações dos solos, geomorfologia e geologia, bem como do uso e cobertura de terras, têm sido realizados, uma vez que a geração de informações ambientais tornou-se mais eficiente e rápida, devido à utilização de dados originados dos sensores orbitais de imageamento da superfície da Terra. Vários autores têm utilizado a compartimentação da paisagem, visando à manutenção sustentável de recursos naturais, em particular os solos (Guerra \& Cunha 1996, Crepani et al. 2001, Dias et al. 2002, Resende et al. 2002, Bernardes 2006, Lacerda et al. 2006, Martins et al. 2006).

Para Resende \& Rezende (1983), o solo é considerado o melhor estratificador de ambientes. Assim, considera-se que o conhecimento detalhado dos domínios pedológicos, associados às unidades geológicas e geomorfológicas de uma determinada região, pode fornecer dados importantes para o planejamento e a conservação de recursos naturais (Resende et al. 2007). Guerra \& Cunha (1996) argumentam que o estudo dos pedoambientes integra uma visão conjunta do comportamento das condições naturais e das atividades humanas neles desenvolvidas, uma vez que mudanças significativas, em quaisquer dessas unidades, podem gerar alterações no meio ambiente. Assim, os pedoambientes constituem unidades importantes de avaliação de uma região, devido à caracterização dos recursos naturais, associada ao uso e ocupação antrópica.

Nessa perspectiva, este trabalho objetivou a caracterização dos principais solos e suas relações com o meio físico e vegetação nativa associada, na região de Santa Tereza, Estado do Tocantins, a fim de se caracterizar e individualizar unidades pedoambientais.

\section{MATERIAL E MÉTODOS}

A área de estudo foi selecionada em razão da ocorrência de classes de solo representativas do Estado do Tocantins. Esta correspondeu a um transecto pedológico, no sentido oeste-leste, com 50,5 km de extensão, localizado na região centro-leste do Estado do Tocantins, delimitado pelas coordenadas UTM de $8.872 .129 \mathrm{mN}$ e $8.857 .794 \mathrm{mN}$ e $182.305 \mathrm{mE}$ e $225.710 \mathrm{mE}$, totalizando 622,24 $\mathrm{Km}^{2}$ (Figura 1). A área está situada nos municípios de Palmas (proximidades do Distrito de Buritirana), Santa Tereza do Tocantins, Lagoa do Tocantins e Novo Acordo, sendo delimitada por meio da base cartográfica digital disponível na escala 1:100.000, do Naturatins (2004), e da base temática de solos na escala 1:250.000, da Seplan (Tocantins 2005).

Ao longo do transecto pedológico, foram descritos e amostrados sete perfis de solos (P1, P2, P3, P4, P5, P6 e P7) representativos da área, todos sob vegetação nativa original.

As descrições morfológicas e coleta de amostras para análises físicas e químicas (horizontes A e B ou $\mathrm{A}$ e C) dos perfis dos solos foram realizadas de acordo com Santos et al. (2005). As análises físicas realizadas foram granulometria e argila dispersa em água. A partir dos dados obtidos, foram calculados os valores da relação silte/argila e o índice de floculação, dados pela relação de argila total após dispersão (AT) e argila dispersa em água $(\mathrm{ADA}=\mathrm{AT}-\mathrm{ADA} / \mathrm{AT} \times 100)$, segundo metodologias descritas pela Embrapa (1997).

As análises químicas compreenderam a determinação do complexo sortivo ( $\mathrm{pH}$ em água, cálcio, magnésio, potássio, alumínio e acidez potencial), fósforo e matéria orgânica, de acordo com Embrapa (1997). A partir dos dados obtidos, calcularam-se os valores da soma de bases (S), CTC (T), CTC efetiva $(\mathrm{t})$, saturação de bases $(\mathrm{V})$ e saturação por $\mathrm{Al}^{+3}(\mathrm{~m})$. As análises foram realizadas nos Laboratórios de Física e Química do Solo, da Faculdade de Agronomia e Medicina Veterinária da Universidade de Brasília. A partir dos resultados das análises físicas e químicas, os solos foram classificados, segundo o Sistema Brasileiro de Classificação de Solos - SiBCS (Embrapa 2006), até o quarto nível categórico. 


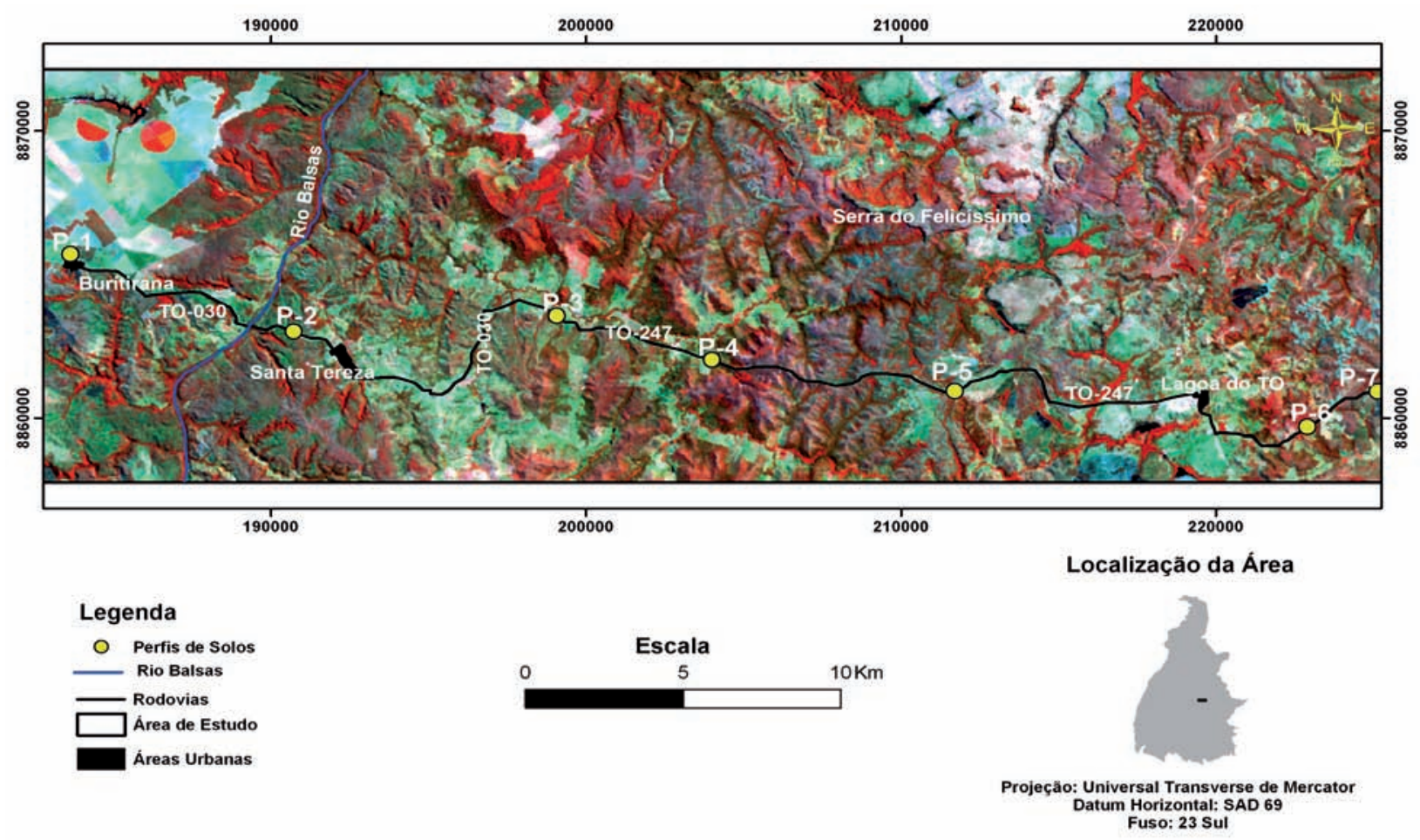

Figura 1. Localização da área de estudo (Região de Santa Tereza do Tocantins, TO, 2006).

O Mapa de Classes de Declividade da área em estudo foi gerado utilizando-se os dados digitais de pontos cotados, curvas de nível e hidrografia da base cartográfica do Naturatins (2004), na escala 1:100.000. Por meio do interpolador Topo to Raster, construiu-se o Modelo Digital do Terreno (MDT), utilizando-se o software ArcGIS 9.1. A partir do MDT, foi realizado o fatiamento das seguintes classes de declividade: $0-3 \%$ (relevo plano), 3-8\% (relevo suave ondulado), 8-20\% (relevo ondulado), $20-45 \%$ (relevo forte ondulado) e $45-64 \%$ (relevo montanhoso).

O Mapa de Uso e Cobertura de Terras, com enfoque para a cobertura vegetal natural, foi elaborado a partir de imagem do sensor remoto $\mathrm{TM}$, do programa Landsat 5 , correspondente à órbita/ponto $222 / 67$, datada de 18/08/2006, utilizando-se as bandas 3, 4 e 5, na composição colorida 4R5G3B. Para a individualização de classes de uso e ocupação das terras, foi realizada a classificação não-supervisionada, com o classificador ISODATA, disponível no software ENVI 4.3, com correções manuais mediante interpretação visual da imagem, visando à otimização da representatividade do uso da área de estudo. Foram individualizadas dez classes: Agricultura, Área urbana, Cerrado denso, Cerrado ralo, Cerrado típico,
Corpos d'água, Mata, Campo/Pastagem, Vegetação secundária e Solo exposto. As descrições das classes mapeadas da cobertura vegetal natural do bioma Cerrado foram realizadas de acordo com Ribeiro \& Walter (1998).

A quantificação das classes temáticas dos mapas gerados foi realizada por meio do software ArcGIS 9.1. Para avaliar a exatidão do Mapa de Uso e Cobertura de Terras, foi utilizado o coeficiente Kappa, conforme descrito por Congalton \& Green (1999).

A avaliação da aptidão agrícola das terras, relativa aos perfis de solos estudados, foi realizada com base na metodologia descrita por Ramalho Filho \& Beek (1995). Os dados morfológicos, físicos e químicos dos solos, juntamente com as observações realizadas no campo e interpretação dos mapas gerados de Classes de Declividade e do Uso e Cobertura de Terras, possibilitaram a utilização do quadro-guia de referência de região de clima tropical úmido, para a classificação da aptidão agrícola das terras, em função dos tipos de manejo A, B e C adotados, considerando-se o grau limitante mais forte.

As unidades pedoambientais compreenderam uma porção territorial representativa dos solos, relevo, aptidão agrícola das terras e cobertura vegetal da área estudada. Para a sua individualização, foram 
utilizados os dados gerados neste trabalho e os mapas de solos elaborados pelo IBGE (2006) e pela Seplan (Tocantins 2005), ambos em escala 1:250.000, associados às informações disponíveis dos demais recursos naturais.

\section{RESULTADOS E DISCUSSÃO}

Os atributos morfológicos descritos nos perfis e as análises físicas e químicas permitiram a classificação dos solos, segundo o SiBCS (Embrapa 2006), em Perfil 1 (P1) - Latossolo Vermelho Distrófico típico; Perfil 2 (P2) - Plintossolo Pétrico Concrecionário latossólico; Perfil 3 (P3) - Latossolo VermelhoAmarelo Distrófico típico; Perfil 4 (P4) - Cambissolo Háplico Tb Distrófico típico; Perfil 5 (P5) - Neossolo Quartzarênico Órtico típico; Perfil 6 (P6) - Neossolo Regolítico Distrófico típico; e Perfil 7 (P7) - Neossolo Quartzarênico Órtico típico. As descrições morfológicas completas dos perfis estudados encontram-se disponíveis em Santana (2008). Conforme esperado, verifica-se a ocorrência de Cambissolos Háplicos na área de Neossolos Litólicos.

As análises físicas, cujos resultados estão apresentados na Tabela 1, permitiram a classificação textural dos solos, que mostra variações desde argilosa até arenosa, ao longo do transecto pedológico, devido à variação granulométrica e mineralógica do material de origem. De modo geral, o teor de argila tende a aumentar com a profundidade, em direção aos horizontes diagnósticos dos solos estudados, uma tendência bem definida no Neossolo Regolítico (P6), que preserva a estratificação horizontalizada da litologia de origem, com estratos superiores mais arenosos e inferiores mais argilosos. Segundo Prevedello (1996) e Oliveira (2005), as classes texturais presentes ao longo do perfil de um solo têm importantes implicações no comportamento agrícola, principalmente em relação ao período de utilização e intensidade no uso de máquinas, bem como à disponibilidade de água, aeração, condutividade térmica, drenagem e erodibilidade.

A relação silte/argila nos solos apresentou valores muito baixos para os Latossolos e Plintossolos (respectivamente P1, P3 e P2), mostrando o elevado grau de intemperização destes (Embrapa 2006). Quanto ao Cambissolo (P4), a relação silte/argila não foi um bom indicador para se determinar o grau de intemperismo do solo e sua classificação. A justificativa para o baixo valor da relação silte/argila

Tabela 1. Resultados das análises físicas dos perfis dos solos estudados (P1, P2, P3, P4, P5, P6 e P7).

\begin{tabular}{|c|c|c|c|c|c|c|c|c|}
\hline Horizonte & $\begin{array}{l}\text { Profundidade } \\
\mathrm{cm}\end{array}$ & Areia & $\begin{array}{l}\text { Argila } \\
\mathrm{g} \mathrm{kg}^{-1}\end{array}$ & Silte & Silte/Argila & $\begin{array}{l}\mathrm{ADA}^{1} \\
\mathrm{~g} \mathrm{~kg}^{-1}\end{array}$ & $\begin{array}{c}\mathrm{IF}^{2} \\
\text { dag kg-1 }\end{array}$ & $\begin{array}{l}\text { Classes } \\
\text { texturais }\end{array}$ \\
\hline \multicolumn{9}{|c|}{ Perfil 1 - Latossolo Vermelho Distrófico típico - LVd } \\
\hline A & $0-10$ & 385,3 & 435,5 & 179,2 & 0,41 & 165,9 & 61,90 & Argilosa \\
\hline $\mathrm{Bw}$ & $40+$ & 239,9 & 595,8 & 164,3 & 0,27 & 41,0 & 93,00 & Argilosa \\
\hline \multicolumn{9}{|c|}{ Perfil 2 - Plintossolo Pétrico Concrecionário latossólico - FFc } \\
\hline Ac & $0-40$ & 583,9 & 324,8 & 91,3 & 0,28 & 102,4 & 68,47 & Franco-argilo-arenosa \\
\hline $\mathrm{Bc} / \mathrm{F}$ & $60-120$ & 424,0 & 454,8 & 121,2 & 0,26 & 110,9 & 75,61 & Argilosa \\
\hline \multicolumn{9}{|c|}{ Perfil 3 - Latossolo Vermelho-Amarelo Distrófico típico - LVAd } \\
\hline A & $0-15$ & 490,5 & 305,7 & 203,8 & 0,66 & 101,9 & 66,66 & Franco-argilo-arenosa \\
\hline $\mathrm{Bw}$ & 35 & 485,5 & 383,4 & 131,1 & 0,34 & 17,3 & 95,48 & Irenosa \\
\hline \multicolumn{9}{|c|}{ Perfil 4 - Cambissolo Háplico Tb Distrófico típico - $C X b d$} \\
\hline A & $0-30$ & 323,2 & 426,0 & 250,8 & 0,58 & 243,9 & 42,74 & Argilosa \\
\hline $\mathrm{Bi}$ & $30-65$ & 182,5 & 529,9 & 287,6 & 0,54 & 20,2 & 96,82 & Argilosa \\
\hline \multicolumn{9}{|c|}{ Perfil 5 - Neossolo Quartzarênico Órtico típico - RQo } \\
\hline A & $0-10$ & 846,9 & 80,3 & 72,8 & - & - & - & Arenosa \\
\hline $\mathrm{C}$ & $10+$ & 708,7 & 160,7 & 130,6 & - & - & - & Franco-arenosa \\
\hline \multicolumn{9}{|c|}{ Perfil 6 - Neossolo Regolítico Distrófico típico - RRd } \\
\hline A & $0-20$ & 796,0 & 120,7 & 83,3 & - & - & - & Areia franca \\
\hline $\mathrm{Cr}$ & & 616,7 & 232,0 & 151,3 & - & & - & Franco-argilo-arenosa \\
\hline \multicolumn{9}{|c|}{ Perfil 7 - Neossolo Quartzarênico Órtico típico - RQo } \\
\hline A & $0-5$ & 896,7 & 80,4 & 22,9 & - & - & - & Arenosa \\
\hline $\mathrm{C}$ & $5-120$ & 849,4 & 120,5 & 30,1 & - & - & - & Areia franca \\
\hline
\end{tabular}

${ }^{1}$ Argila dispersa em água; ${ }^{2}$ Índice de floculação. 
pode ser o material de origem, uma rocha pelítica, pré-intemperizada, com baixos teores de silte, não representando, portanto, evolução pedogenética. Estes resultados concordam com os obtidos por Almeida et al. (1997), os quais relatam que a variação do material de origem, nos Cambissolos, torna a relação silte/argila um indicador ineficiente para sua diferenciação, particularmente em litologias de origem sedimentar.

Nos solos avaliados, os teores de argila dispersa em água foram maiores nos horizontes $\mathrm{A}$, em relação aos horizontes $\mathrm{Bw}(\mathrm{P} 1$ e $\mathrm{P} 3), \mathrm{Bc} / \mathrm{F}(\mathrm{P} 2)$ e Bi (P4), discordando de Costa et al. (2006), ao analisar um Cambissolo Húmico, no qual encontrou teores de argila dispersa em água menores no primeiro horizonte, relacionados ao conteúdo de matéria orgânica, cátions trocáveis, ciclos de umedecimento e secagem e atividade biológica, especialmente raízes, alguns destes favorecendo a floculação da argila. No presente trabalho, os menores resultados de argila dispersa em água e maiores índices de floculação nos horizontes Bw, em relação aos horizontes A, concordaram com Resende et al. (2007), que relataram que os Latossolos apresentam altos índices de floculação, em função do enriquecimento de sesquióxidos de Fe e Al, que são agentes agregantes dos solos, onde o índice de floculação pode atingir 100\%. Moura Filho \& Buol (1972) constataram que os Latossolos com maior grau de intemperismo apresentam forma- ção de microagregados resistentes à dispersão, fato corroborado por Ferreira et al. (1999), que demonstraram que os Latossolos gibbsíticos desenvolvem estrutura granular muito mais estável, em relação aos Latossolos caulínicos. Assim, os maiores índices de floculação avaliados nos horizontes subsuperficiais dos solos com alto grau de intemperismo podem ser justificados pela mineralogia sesquioxídica, que deve ter superado o poder agregante da matéria orgânica nos horizontes superficiais. Nos perfis P5, P6 e P7, não foi analisada a argila dispersa em água (ADA), por se tratarem de solos arenosos.

Os resultados das análises químicas (Tabela 2) apresentaram características bem semelhantes, provavelmente em função dos materiais de origem, constituídos por rochas sedimentares pré-intemperizadas, de natureza psamítica a pelítica. Os solos analisados apresentaram valores baixos de $\mathrm{pH}$ em $\mathrm{H}_{2} \mathrm{O}$, no horizonte $\mathrm{A}$, caracterizando solos fortemente ácidos (P6) e medianamente ácidos (P1, P2, P3, P4 e P7) a fracamente ácido (P5), segundo a Comissão de Fertilidade de Solos de Goiás (1988).

$\mathrm{O}$ alumínio trocável $\left(\mathrm{Al}^{3+}\right)$ e acidez potencial $\left(\mathrm{H}^{+}+\mathrm{Al}^{3+}\right)$ foram, geralmente, maiores nos horizontes A dos solos estudados, em decorrência da acidez gerada pela matéria orgânica. Para Resende et al. (2007), os Cambissolos sob vegetação de Cerrado, frequentemente, apresentam altos teores de alumínio trocável, sendo atestado que o P4 foi o solo que

Tabela 2. Resultados das análises químicas dos perfis dos solos estudados (P1, P2, P3, P4, P5, P6 e P7).

\begin{tabular}{|c|c|c|c|c|c|c|c|c|c|c|c|c|c|c|}
\hline Horizonte & $\begin{array}{l}\text { Profundidade } \\
\mathrm{cm}\end{array}$ & $\begin{array}{c}\mathrm{pH} \\
\mathrm{H}_{2} \mathrm{O}\end{array}$ & $\mathrm{Ca}^{2+}+\mathrm{Mg}^{2+}$ & $\mathrm{K}^{+}$ & $\begin{array}{c}\mathrm{S}^{1} \\
\mathrm{Cl}\end{array}$ & $\begin{array}{l}\mathrm{Al}^{3+} \\
\text { olc kg }\end{array}$ & $\mathrm{H}^{+}+\mathrm{Al}^{3+}$ & $\mathrm{T}^{2}$ & $t^{3}$ & $\mathrm{~V}^{4}$ & $\mathrm{~m}^{5}$ & $\begin{array}{c}\mathrm{P} \\
\mathrm{mg} \mathrm{kg}^{-1}\end{array}$ & $\begin{array}{l}\mathrm{MO}^{6} \\
\mathrm{Hg}\end{array}$ & $\mathrm{C}^{7}$ \\
\hline \multicolumn{15}{|c|}{ Perfil 1 - Latossolo Vermelho Distrófico típico - LVd } \\
\hline A & $0-10$ & 5,48 & 0,70 & 0,16 & 0,86 & 1,33 & 10,72 & 11,58 & 2,19 & 7,42 & 60,81 & 1,57 & 68,81 & 39,84 \\
\hline $\mathrm{Bw}$ & $40^{+}$ & 5,72 & 0,00 & 0,01 & 0,01 & 0,00 & 1,13 & 1,08 & 0,01 & 1,10 & 0,00 & 1,57 & 11,00 & 6,35 \\
\hline \multicolumn{15}{|c|}{ Perfil 2 - Plintossolo Pétrico Concrecionário latossólico - FFc } \\
\hline A & $0-40$ & 5,15 & 0,33 & 0,11 & 0,45 & 1,88 & 9,17 & 9,62 & 2,33 & 4,62 & 81,12 & 1,94 & 42,70 & 24,65 \\
\hline $\mathrm{Bc} / \mathrm{F}$ & $60-120$ & 5,46 & 0,03 & 0,02 & 0,05 & 0,07 & 2,40 & 2,45 & 0,12 & 1,97 & 61,21 & 1,08 & 12,57 & 7,26 \\
\hline \multicolumn{15}{|c|}{ Perfil 3 - Latossolo Vermelho-Amarelo Distrófico típico - LVAd } \\
\hline A & $0-15$ & 5,37 & 0,60 & 0,28 & 0,88 & 1,32 & 5,90 & 6,78 & 2,20 & 13,02 & 59,88 & 1,82 & 31,47 & 18,17 \\
\hline $\mathrm{Bw}$ & $35^{+}$ & 5,33 & 0,17 & 0,04 & 0,21 & 0,37 & 1,77 & 1,98 & 0,58 & 10,50 & 63,73 & 1,20 & 7,60 & 4,39 \\
\hline \multicolumn{15}{|c|}{ Perfil 4 - Cambissolo Háplico Tb Distrófico típico - CXbd } \\
\hline A & $0-30$ & 5,14 & 0,47 & 0,30 & 0,77 & 1,77 & 5,42 & 6,19 & 2,53 & 12,39 & 69,74 & 3,21 & 38,00 & 21,94 \\
\hline $\mathrm{Bi}$ & $30-65$ & 5,01 & 0,10 & 0,07 & 0,17 & 1,30 & 2,28 & 2,45 & 1,47 & 6,94 & 88,46 & 1,70 & 2,27 & 1,31 \\
\hline \multicolumn{15}{|c|}{ Perfil 5 - Neossolo Quartzarênico Órtico típico - RQo } \\
\hline A & $0-10$ & 5,90 & 0,60 & 0,54 & 1,14 & 0,16 & 1,71 & 2,95 & 1,33 & 39,91 & 12,25 & 3,89 & 6,57 & 3,79 \\
\hline $\mathrm{C}$ & $10^{+}$ & 4,86 & 0,30 & 0,02 & 0,32 & 0,92 & 1,50 & 1,82 & 1,24 & 17,60 & 74,10 & 2,32 & 1,82 & 1,05 \\
\hline \multicolumn{15}{|c|}{ Perfil 6 - Neossolo Regolítico Distrófico típico - RRd } \\
\hline A & $0-20$ & 4,94 & 0,27 & 0,11 & 0,38 & 0,75 & 3,58 & 3,95 & 1,13 & 9,50 & 66,20 & 3,09 & 7,72 & 4,46 \\
\hline $\mathrm{Cr}$ & $20-100$ & 5,06 & 0,30 & 0,09 & 0,39 & 0,55 & 2,08 & 2,46 & 0,94 & 15,70 & 58,72 & 1,94 & 3,90 & 2,25 \\
\hline \multicolumn{15}{|c|}{ Perfil 7 - Neossolo Quartzarênico Órtico típico - Rqo } \\
\hline A & $0-5$ & 5,03 & 0,57 & 0,14 & 0,71 & 0,73 & 3,50 & 4,21 & 1,44 & 16,88 & 50,89 & 4,13 & 7,69 & 4,44 \\
\hline $\mathrm{C}$ & $5-120$ & 5,16 & 0,20 & 0,06 & 0,26 & 0,25 & 1,30 & 1,56 & 0,51 & 16,47 & 48,37 & 1,45 & 1,59 & 0,92 \\
\hline
\end{tabular}

${ }^{1}$ Soma de bases; ${ }^{2} \mathrm{CTC}$ potencial (pH 7,0); ${ }^{3}$ CTC efetiva; ${ }^{4}$ Saturação de bases; ${ }^{5}$ Saturação por alumínio; ${ }^{6}$ Matéria orgânica; $;$ Carbono Orgânico. 
apresentou o maior valor de $\mathrm{Al}^{3+}$ no horizonte $\mathrm{Bi}$, em relação aos outros perfis, com 1,30 $\mathrm{cmol}_{\mathrm{c}} \mathrm{kg}^{-1}$.

Foram constados baixos teores de $\mathrm{Ca}^{2+}+\mathrm{Mg}^{2+}$ nos perfis estudados e, consequentemente, baixa saturação de bases no complexo coloidal, caracterizando todos os solos como distróficos, conforme Embrapa (2006). Estes resultados podem ser atribuídos à pobreza química dos materiais de origem (folhelhos, siltitos e, principalmente, arenitos), que não apresentam minerais primários portadores de elementos nutrientes. Os teores de fósforo disponíveis foram baixos em todos os solos estudados, condição comum nos solos brasileiros, segundo Raij (1991).

A saturação por alumínio foi alta em quase todos os horizontes de todos os solos, sendo grande parte da capacidade de troca de cátions CTC $(\mathrm{T})$ ocupada com o $\mathrm{H}^{+}+\mathrm{Al}^{3+}$, aumentando, assim, a competição de $\mathrm{Al}^{3+}$ com os cátions de outros elementos, tanto nos minerais argilosos quanto na matéria orgânica, tal como descrito por Muggler et al. (1996), que constataram que estes tipos de solos apresentam CTC saturada pelo cátion $\mathrm{Al}^{3+}$.

Os teores de matéria orgânica nos horizontes A foram maiores nos solos argilosos e com cobertura vegetal mais densa, em relação aos solos arenosos, com uma vegetação menos densa, concordando com relatos de Anjos et al. (1999). O Latossolo Vermelho (P1), sob vegetação de Cerrado denso a típico, obteve o valor mais elevado de matéria orgânica $\left(68,81 \mathrm{~g} \mathrm{~kg}^{-1}\right)$, enquanto, nos Neossolos Quartzarênicos P5 e P7, sob cobertura vegetal de Cerrado ralo a campo, foram obtidos os menores teores de matéria orgânica (6,57 $\mathrm{g} \mathrm{kg}^{-1}$ e 7,69 $\mathrm{g} \mathrm{kg}^{-1}$, respectivamente), concordando com Vieira (1988) e Resende et al. (2007). Para o P3, Latossolo Vermelho-Amarelo, foi encontrado valor médio de matéria orgânica de $31,47 \mathrm{~g} \mathrm{~kg}^{-1}$.

Os perfis de Neossolos (P5, P6 e P7), que mostraram classes texturais variando de franco-argiloarenosa até arenosa, apresentaram os mais baixos teores de matéria orgânica e, consequentemente, de carbono orgânico. Conforme descrito por Bayer et al. (2000), a textura arenosa confere baixa fixação da matéria orgânica, além da baixa taxa de deposição orgânica, uma vez que a vegetação nativa é de Cerrado ralo a campo. Acrescenta-se a temperatura média anual $\left(27^{\circ} \mathrm{C}\right)$ da região, que, também, contribui para elevadas taxas de mineralização do carbono orgânico do solo.

Considerando-se os padrões de fertilidade preconizados pela Comissão de Fertilidade de So- los de Goiás (1988), os solos da área de estudo são dependentes da utilização de práticas de manejo químico, como a calagem, para correção da acidez; por vezes, a gessagem, para minimizar a toxidez de Al em profundidade; e uso intensivo de fertilizantes, em função das suas características químicas.

Com relação à declividade da área de estudo, a Tabela 3 mostra a quantificação das áreas ocupadas pelas classes de declividade, extraídas do mapa gerado de Classes de Declividade (Figura 2), sendo que predominam as classes $0-3 \%$ e $3-8 \%$, caracterizando relevo plano e relevo suave ondulado, porém com áreas aonde a declividade chega a 64\%. Uma das áreas mais declivosas encontra-se na Serra do Felicíssimo, onde ocorre uma das cotas mais altas da área $(450 \mathrm{~m})$.

O mapa de Uso e Cobertura de Terras (Figura 3), da área em pauta, foi individualizado em 10 classes, incluindo classes de vegetação nativa e áreas de uso antrópico, além dos corpos d'água. A quantificação das áreas das classes mapeadas encontra-se na Tabela 4. O Cerrado denso foi o tipo de vegetação de maior ocorrência (19,78\%). A cobertura vegetal nativa, incluindo Cerrado denso, Cerrado típico, Cerrado ralo e Mata, totaliza 63,5\% da área de estudo. A classe Agricultura ocorre em pequenas áreas, representada pela implantação de cultivos anuais, sendo a principal atividade econômica a criação de bovinos.

O coeficiente Kappa, utilizado para avaliar a exatidão do mapa gerado de Uso e Cobertura de Terras da área estudada, foi calculado em $62,25 \%$, sendo considerado como muito bom, conforme parâmetros adotados por Landis \& Koch (1997).

A avaliação da Aptidão Agrícola das Terras, na área estudada, foi assim classificada:

- Classe 2(b)c: terras constituídas pelos Latossolos Vermelhos (P1) e Latossolos Vermelho-

Tabela 3. Quantificação das áreas das classes de declividade (Região de Santa Tereza do Tocantins, TO, 2007).

\begin{tabular}{crr}
\hline Classes de & \multicolumn{2}{c}{ Área } \\
\cline { 2 - 3 } Declividade & \multicolumn{1}{c}{$\mathrm{km}^{2}$} & \multicolumn{1}{c}{$\%$} \\
\hline $0-3 \%$ & 267,60 & 43,00 \\
$3-8 \%$ & 186,00 & 30,00 \\
$8-20 \%$ & 127,00 & 20,00 \\
$20-45 \%$ & 41,54 & 6,98 \\
$45-64 \%$ & 0,10 & 0,02 \\
Total & 622,24 & 100,00 \\
\hline
\end{tabular}




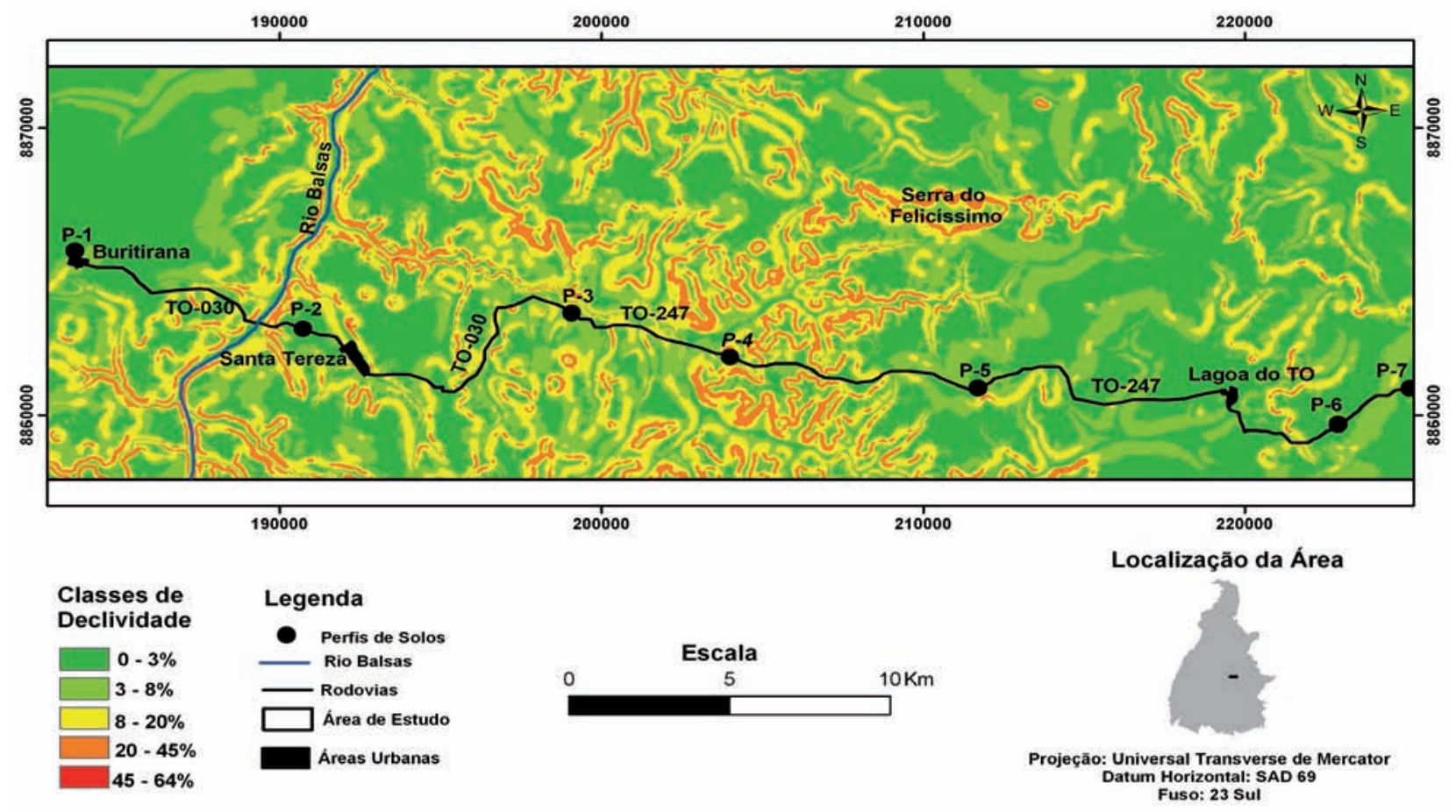

Figura 2. Mapa de Classes de Declividade da área de estudo (Região de Santa Tereza do Tocantins, TO, 2007).

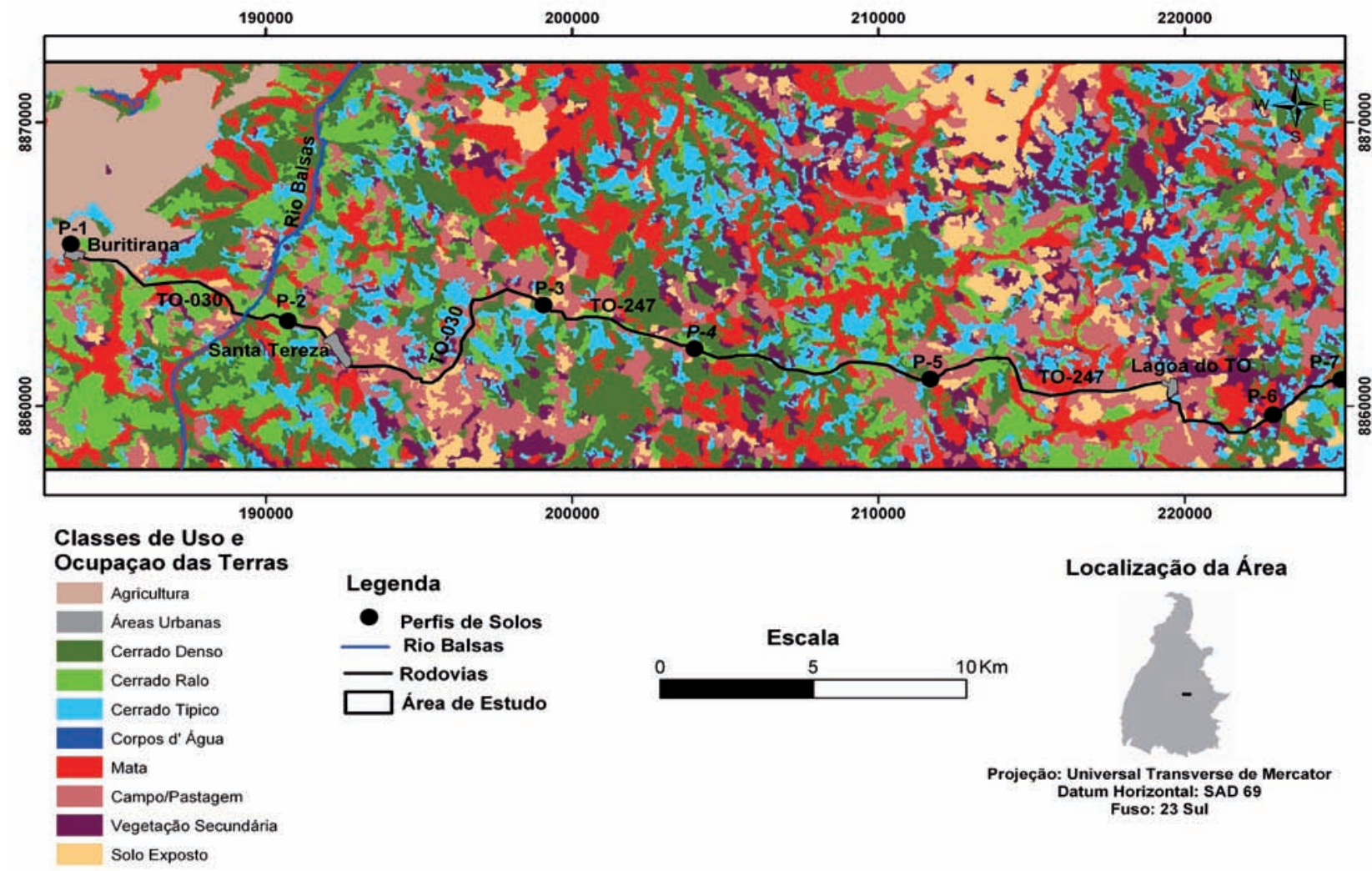

Figura 3. Mapa de Uso e Cobertura de Terras da área de estudo (Região de Santa Tereza do Tocantins, TO, 2006). 
Tabela 4. Quantificação das classes de uso e cobertura (Região de Santa Tereza do Tocantins, TO, 2006).

\begin{tabular}{lrr}
\hline \multirow{2}{*}{ Classes de uso e ocupação } & \multicolumn{2}{c}{ Área } \\
\cline { 2 - 3 } & \multicolumn{1}{c}{$\mathrm{km}^{2}$} & \multicolumn{1}{c}{$\%$} \\
\hline Agricultura & 34,80 & 5,6 \\
Área urbana & 0,86 & 0,1 \\
Cerrado denso & 123,09 & 19,8 \\
Cerrado ralo & 77,43 & 12,4 \\
Cerrado típico & 85,98 & 13,8 \\
Corpos d'água & 2,66 & 0,4 \\
Mata & 108,63 & 17,5 \\
Campo/Pastagem & 89,39 & 14,4 \\
Vegetação secundária & 57,56 & 9,3 \\
Solo exposto & 41,84 & 6,7 \\
Total & 622,24 & 100,0 \\
\hline
\end{tabular}

Amarelos (P3), cuja classificação concorda com o mapeamento de aptidão agrícola, na maioria das classes dos Latossolos da região do Distrito Federal, realizado pela Embrapa (1978). O principal fator limitante é a baixa fertilidade, demonstrada pelos baixos teores de soma e saturação por bases (V), baixa CTC (T) e altos valores de saturação por alumínio (m) (Tabela 2). Em contrapartida, tratamse de solos profundos, bem estruturados, com boas condições de drenagem, desenvolvidos em relevo plano a suave ondulado, dificilmente ultrapassando $8 \%$ de declividade, o que facilita a mecanização. São portadores de boas propriedades físicas, dificultando a instalação de processos erosivos, quando bem manejados, segundo recomendações descritas por Bertoni \& Lombardi Neto (1990);

- Classe 4p: Plintossolos Pétricos (P2), que apresentam alta limitação de fertilidade (Tabela 2) e forte limitação para a mecanização, devido à presença abundante a comum de concreções e/ou nódulos ferruginosos, apesar de evoluírem em relevo plano a suave ondulado;

- Classe 4(p): terras associadas aos Cambissolos Háplicos (P4), que apresentam limitações quanto à fertilidade (Tabela 2), susceptibilidade à erosão e restrições à mecanização, em função do relevo, por tratarem-se de solos desenvolvidos em classes de declividades maiores que 12\% (Figura 2), além da ocorrência de cascalhos no horizonte superficial. $\mathrm{Na}$ classe 4(p), encontram-se, também, as terras representadas pelos Neossolos Regolíticos (P6), onde a grande limitação está relacionada à deficiência de fertilidade, além da susceptibilidade à erosão, em virtude da textura arenosa nos horizontes superfi- ciais. Entretanto, o horizonte C, de textura mais argilosa, em relação aos horizontes $\mathrm{C}$ dos perfis $\mathrm{P} 5$ e P7, confere uma menor deficiência de água, em relação aos Neossolos Quartzarênicos, o que permite que estes solos sejam alocados em classe de aptidão agrícola menos restritiva. A correlação da vegetação nativa, nesse ambiente, contribui como parâmetro auxiliar, onde se verifica desenvolvimento de Cerrado típico, e, em P5 e P7, encontra-se Cerrado ralo a campo;

- Classe 5(n): classe com ocorrência de Neossolos Quartzarênicos (P5 e P7), que possuem forte restrição em três dos cinco fatores limitantes, exceto em relação à deficiência de oxigênio e declividade do terreno, pois se desenvolvem em relevo plano a suave ondulado. Porém, constituem solos muito susceptíveis aos processos erosivos, configurando um ambiente frágil, do ponto de vista de resistência à erosão, pois sua textura arenosa favorece a instalação de processos erosivos, principalmente quando mal manejados;

- Classe 6: classe representada pelos Neossolos Litólicos, que apresentam limitações severas, como declividade e pouca profundidade dos solos, constituindo terras inaptas para o uso agrícola.

Foi possível individualizar quatro unidades pedoambientais (Figura 4), com suas principais características apresentadas na Tabela 5, com enfoque para os atributos pedológicos e geológicos, declividade, cobertura vegetal e aptidão agrícola das terras:

- Unidade pedoambiental I: com predominância dos Latossolos, encontra-se localizada na região noroeste da área de estudo, englobando o perfil pedológico P1 (Latossolo Vermelho) estudado. O relevo é plano a suave ondulado, em classes de declividade de $0-8 \%$, com predomínio da classe $0-3 \%$, que corresponde a $80 \%$ do total da área. Apresenta terras pertencentes à classe de aptidão 2(b)c e a vegetação nativa associada é o Cerrado denso a típico. Como representa terras com elevado potencial agrícola para culturas de ciclo curto, a vegetação nativa já se encontra praticamente substituída por lavouras anuais, com utilização de alto nível tecnológico na agricultura. Unidades ambientais semelhantes à unidade pedoambiental I são comuns no território brasileiro, podendo-se citar o trabalho de Bernardes (2006), que caracterizou um pedoambiente similar, no Complexo de Serra Negra (MG), no qual a maior parte das atividades agrícolas está implantada em áreas Latossólicas; 


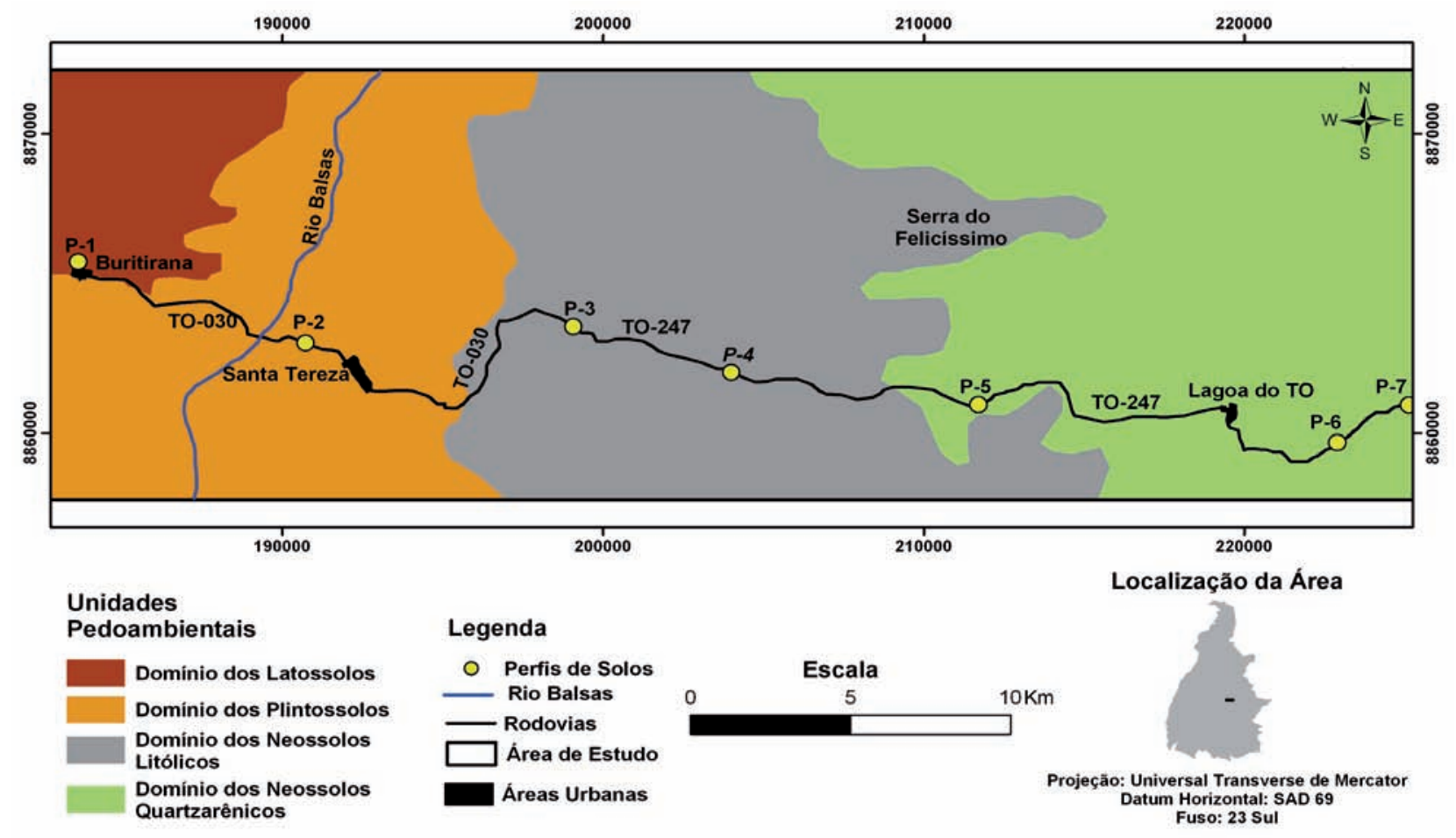

Figura 4. Mapa de Unidades Pedoambientais da área de estudo (Região de Santa Tereza do Tocantins, TO, 2006).

Tabela 5. Caracterização das unidades pedoambientais (Região de Santa Tereza do Tocantins, TO, 2006).

\begin{tabular}{|c|c|c|c|c|c|c|}
\hline $\begin{array}{c}\text { Unidades } \\
\text { pedoambientais }\end{array}$ & Solos & Declividade & Geologia & Vegetação & $\begin{array}{l}\text { Aptidão } \\
\text { agrícola }\end{array}$ & Área \\
\hline $\begin{array}{c}\text { Unidade } \\
\text { pedoambiental I }\end{array}$ & Domínio dos Latossolos & $80 \%$ plano & Formação Pimenteiras & $\begin{array}{l}\text { Cerrado denso } \\
\text { a típico }\end{array}$ & $2(b) c$ & $7 \%$ \\
\hline $\begin{array}{c}\text { Unidade } \\
\text { pedoambiental II }\end{array}$ & Domínio dos Plintossolos & $\begin{array}{c}66 \% \text { plano } \\
\text { a suave ondulado }\end{array}$ & $\begin{array}{l}\text { Formação Pimenteiras } \\
\text { e Serra Grande }\end{array}$ & $\begin{array}{l}\text { Cerrado típico } \\
\text { a ralo }\end{array}$ & $4 \mathrm{p}$ & $25 \%$ \\
\hline $\begin{array}{c}\text { Unidade } \\
\text { pedoambiental III }\end{array}$ & $\begin{array}{c}\text { Domínio dos } \\
\text { Neossolos Litólicos }+ \\
\text { Cambissolos Háplicos }\end{array}$ & $\begin{array}{l}44,5 \% \text { ondulado } \\
\text { a forte ondulado }\end{array}$ & Formação Pimenteiras & $\begin{array}{l}\text { Cerrado típico } \\
\text { a ralo }\end{array}$ & 6 a $4(p)$ & $33 \%$ \\
\hline $\begin{array}{c}\text { Unidade } \\
\text { pedoambiental IV }\end{array}$ & $\begin{array}{c}\text { Domínio dos Neossolos } \\
\text { Quartzarênicos + Neosso- } \\
\text { los Regolíticos }\end{array}$ & $\begin{array}{l}89 \% \text { plano a } \\
\text { suave ondulado }\end{array}$ & $\begin{array}{l}\text { Formação Cabeças, } \\
\text { Poti e Longá }\end{array}$ & $\begin{array}{c}\text { Cerrado ralo } \\
\text { a formações } \\
\text { campestres }\end{array}$ & $\begin{array}{l}5(\mathrm{n}) \mathrm{a} \\
4(\mathrm{p})\end{array}$ & $35 \%$ \\
\hline
\end{tabular}

$2(b) c=$ terras regulares para lavouras no nível de manejo C, restrita no B e inapta no nível A; 4p = terras regulares para pastagem plantada no nível de manejo B; 4(p) = terras restritas para pastagem plantada no nível de manejo $\mathrm{B} ; 5(\mathrm{n})=$ terras restritas para pastagem natural; $6=$ terras destinadas à preservação da flora e da fauna.

- Unidade pedoambiental II: com predominância dos Plintossolos, encontra-se adjacente à unidade pedoambiental I e é representada pelo perfil P2 (Plintossolo Pétrico). Esses solos apresentam horizontes superficiais concrecionários, de natureza essencialmente ferruginosa, o que dificulta o desempenho em suas operações de manejo, além da presença do horizonte subsuperficial litoplíntico. O relevo predominante varia de plano a suave ondulado, com $66 \%$ da sua área apresentando declividades de $0-8 \%$, declividades de $8-20 \%$ representando $25,5 \%$ da área e o restante apresentando declividade superior a $20 \%$. A vegetação nativa associada é o Cerrado típico a ralo e a classe de aptidão agrícola das terras é $4 p$. Geoambiente semelhante foi descrito por Martins et al. (2006), na planície do Médio Araguaia, no Estado do Tocantins, também constituído por Plintossolos Pétricos, demonstrando a grande expressão territorial desses solos no Estado;

- Unidade pedoambiental III: com predominância dos Neossolos Litólicos + Cambissolos Háplicos, localiza-se na região central da área de estudo, 
limitando-se a oeste com a unidade pedoambiental II. Predominam os Neossolos Litólicos, com horizonte A cascalhento, em associação aos Cambissolos Háplicos (P4), além de pequenas inclusões de Latossolos Vermelho-Amarelos (P3), que não mostram significância nesta unidade. O relevo predominante é ondulado a forte ondulado, com declividades variando de $8-64 \%$, correspondendo a $44,5 \%$ do total da área deste pedoambiente. Esses solos apresentam grande susceptibilidade à erosão e, por outro lado, a mecanização é dificultada, tanto pelo declive acentuado como pela presença de cascalhos no horizonte superficial. São solos vulneráveis à degradação, quando ocupados com atividades antrópicas. As terras desta unidade pertencem ao grupo de aptidão agrícola 6 , destinada à preservação da flora e da fauna e, eventualmente, 4(p) e 2(b)c, nas áreas de ocorrência dos Cambissolos (P4) e Latossolo Vermelho-Amarelo (P3), respectivamente. A vegetação nativa associada é o Cerrado típico a ralo. Nos trabalhos de caracterização de geoambientes, quando a característica ambiental marcante é o relevo declivoso, com desenvolvimento de solos jovens, como ocorre na unidade pedoambiental III, constata-se a fragilidade desses ambientes, os quais devem ser destinados à preservação, tal como descrito no estudo de Dias et al. (2002), desenvolvido no Parque Estadual de Ibitipoca, MG;

- Unidade pedoambiental IV: com predominância dos Neossolos Quartzarênicos + Neossolos Regolíticos, localiza-se na região leste da área de estudo, limitada a oeste pela unidade pedoambiental III. É constituída, predominantemente, por Neossolos Quartzarênicos (P5 e P7) e, subordinadamente, Neossolos Regolíticos (P6). Estes solos são pedogeneticamente jovens, porém profundos e arenosos, o que facilita a perda de água por percolação. O Neossolo Regolítico (P6) apresenta melhores condições hídricas, devido à estratificação horizontalizada original, com materiais de origem psamítica, nos horizontes superficiais, e materiais de origem pelítica, nos horizontes subsequentes, o que contribui com uma maior retenção de água. O relevo é plano a suave ondulado, onde a classe de declividade $0-8 \%$ compreende $89 \%$ do total da área deste pedoambiente. As terras correspondentes pertencem à classe de aptidão agrícola 5(n) a 4(p), esta última nas áreas de ocorrência de Neossolos Regolíticos, configurando um pedoambiente com baixa intensidade de uso agrícola. A vegetação nativa associada varia de Cerrado típico a ralo, até formações campestres.
As relações pedogeomorfológicas utilizadas neste trabalho, a fim de identificar e caracterizar unidades ambientais, têm sido utilizadas com sucesso por vários pesquisadores, como Dias et al. (2002), Resende et al. (2002), Cunha et al. (2005) e Martins et al. (2006), tendo como objetivo fornecer dados para o planejamento de uso e conservação dos recursos naturais. Deve-se ressaltar que, nas unidades pedoambientais caracterizadas, assim como em outras unidades ambientais brasileiras, quando destinadas ao uso agropecuário, é necessário seguir orientações de uso e manejo, a partir de planejamentos de utilização sustentável das terras. A legislação ambiental deve ser obedecida para a correta utilização de recursos naturais, bem como a alocação de áreas destinadas para reserva legal e conservação das áreas de preservação permanente, além das demais leis que dispõem sobre o meio ambiente.

\section{CONCLUSÕES}

1. Na região de Santa Tereza, no Estado do Tocantins, foram caracterizadas cinco classes de solos, classificados como Latossolos Vermelhos e Vermelho-Amarelos, Plintossolo Pétrico, Cambissolo Háplico, Neossolos Quartzarênicos e Neossolo Regolítico, além da ocorrência comum de Neossolos Litólicos. Representam solos de baixa fertilidade natural, com variação textural e grau de evolução pedogenética fortemente influenciados por materiais de origem psamítica e pelítica e variações do relevo.

2. No Mapeamento de Uso e Cobertura de Terras, constatou-se que $63,5 \%$ do total da área se encontram com cobertura vegetal natural, sem considerar a classe Campo, uma vez que não foi possível sua individualização, sendo que 5,6\% estão utilizados com culturas anuais e a principal atividade econômica é representada pela criação de bovinos.

3. A avaliação da aptidão agrícola das terras permitiu sua classificação em 2(b)c, 4p, 4(p), 5(n) e 6, com predomínio das terras pertencentes às classes de aptidão para pastagem plantada e natural, na área de estudo. As terras da classe 2(b)c estão associadas ao desenvolvimento dos Latossolos e as demais estão relacionadas aos solos jovens, ou de textura arenosa.

4. Foram individualizadas quatro unidades pedoambientais, com características diferenciadas em 
relação aos solos, declividade, aptidão agrícola e associação das terras com a vegetação nativa: (I) domínio dos Latossolos; (II) domínio dos Plintossolos; (III) domínio dos Neossolos Litólicos + Cambissolos Háplicos; e (IV) domínio dos Neossolos Quartzarênicos + Neossolos Regolíticos. A unidade pedoambiental I é destinada à agricultura anual, a unidade II apresenta utilização indicada para pastagem plantada, a unidade III destina-se à conservação ambiental e a unidade IV mostra uso adequado à pastagem natural.

\section{REFERÊNCIAS}

ALMEIDA, J. A.; KAMPF, N.; ALMEIDA, R. Caracterização mineralógica de Cambissolos originados de rochas pelíticas nos patamares do alto rio Itajaí e no planalto de Lajes (SC). Revista Brasileira de Ciências do Solo, Campinas, v. 21, n. 1, p. 181-190, 1997.

ALVARENGA, B. S. et al. O ensino de conceitos e práticas de espectroradiometria laboratorial: estudo de caso com solos do Estado de São Paulo. In: SIMPÓSIO BRASILEIRO DE SENSORIAMENTO REMOTO, 11., 2003, Belo Horizonte. Anais... São José dos Campos: INPE, 2003. p. 739-747.

ANJOS, L. H. C. dos; PEREIRA, M. G.; RAMOS, D. P. Matéria orgânica e pedogênese. In: SANTOS, G. A.; CAMARGO, F. A. de O. (Eds.) Fundamentos da matéria orgânica do solo: ecossistemas tropicais e subtropicais. Porto alegre: Genesis, 1999. p. 9-115.

BAYER, C.; MIELNICZUK, J.; MARTIN NETO, L. Efeitos de sistemas de preparo e de cultura na dinâmica da matéria orgânica e na mitigação das emissões $\mathrm{CO}_{2}$. Revista Brasileira de Ciência do Solo, Viçosa, v. 24, n. 3 , p. 559-607, 2000.

BERNARDES, T. Caracterização do ambiente agrícola do Complexo Serra Negra por meio de sensoriamento remoto e sistema de informação geográfica. 2006. $119 \mathrm{f}$. Dissertação (Mestrado em Solos e Nutrição de Plantas)Universidade Federal de Lavras, Lavras, 2006.

BERTONI, J.; LOMBARDI NETO, F. Conservação do solo. 3. ed. São Paulo: Ícone, 1990.

BRASIL. Ministério do Meio Ambiente. Gestão dos recursos naturais: subsídios à elaboração da Agenda 21 brasileira. Brasília, DF: MMA, 2000.

COMISSÃO DE FERTILIDADE DE SOLOS DE GOIÁS. Recomendações de corretivos e fertilizantes para Goiás: $5^{\text {a }}$ aproximação. Goiânia: UFG/Emgopa, 1988. (Informativo técnico, 1).
CONGALTON, R. G.; GREEN, K. Assessing the accuracy of remotely sensed data: principles and practices. New York: Lewis, 1999.

COSTA, A. et al. Alterações físicas e químicas num Cambissolo húmico nativo após a correção de acidez. Revista de Ciências Agroveterinárias, Lages, v. 5, n. 2, p. 118-130, 2006.

CREPANI, E. et al. Sensoriamento remoto e geoprocessamento aplicados ao zoneamento ecológicoeconômico e ao ordenamento territorial. São José dos Campos: INPE, 2001. (INPE-8454-RPQ/722).

CUNHA, P. et al. Superfícies geomórficas e atributos de Latossolos em uma sequência Arenítico-Basáltica da região de Jaboticabal (SP). Revista Brasileira de Ciência do Solo, Viçosa, v. 29, n. 1, p. 81-90, 2005.

DIAS, H. C. T. et al. Geoambiente do Parque Estadual do Ibitipoca município de Lima Duarte - MG. Revista Árvore, Viçosa, v. 26, n. 6, p.777-786, 2002.

EMPRESA BRASILEIRA DE PESQUISA AGROPECUÁRIA (Embrapa). Levantamento de reconhecimento dos solos do Distrito Federal. Rio de Janeiro: Embrapa/Serviço Nacional de Levantamento e Conservação dos Solos, 1978. (Boletim técnico, n. 53).

EMPRESA BRASILEIRA DE PESQUISA AGROPECUÁRIA (Embrapa). Manual de métodos de análise de solos. Rio de Janeiro: Embrapa/Serviço Nacional de Levantamento e Conservação dos Solos, 1997.

EMPRESA BRASILEIRA DE PESQUISA AGROPECUÁRIA (Embrapa). Sistema brasileiro de classificação de solos. 2. ed. Rio de Janeiro: Embrapa/ Centro Nacional de Pesquisa de Solos, 2006.

FERREIRA, M. M.; FERNANDES, B.; CURI, N. Mineralogia da fração argila e estrutura de Latossolos da região Sudeste do Brasil. Revista Brasileira de Ciência do Solo, Viçosa, v. 23, n. 3, p. 507-514, 1999.

GUERRA, A. J. T.; CUNHA, S. B. Degradação ambiental. In: GUERRA, A. J. T.; CUNHA, S. B. (Orgs.). Geomorfologia e meio ambiente. Rio de Janeiro: Bertrand Brasil, 1996. p. 337-379.

INSTITUTO BRASILEIRO DE GEOGRAFIA E ESTATÍSTICA (IBGE). Mapa de pedologia do Estado do Tocantins: Folha SC-23-Y-A (Ponte Alta do Norte escala 1:250.000). Salvador: IBGE/Gerência de Recursos Naturais e Ambientais, 2006.

INSTITUTO NATUREZA DO TOCANTINS (Naturatins). Base cartográfica digital na escala 1:100.000. Palmas: Naturatins, 2004. 
JORGE, J. A. Física e manejo dos solos tropicais. Campinas: Instituto Campineiro de Ensino Agrícola, 1986.

LACERDA, M. P. C.; NASCIMENTO, R. O.; BARBOSA, I. O. Determinação de pedoformas na Estação Ecológica de Águas Emendadas, DF. In: REUNIÃO BRASILEIRA DE MANEJO E CONSERVAÇÃO DO SOLO E DA ÁGUA, 16., 2006, Aracaju. Anais... Aracaju: SBCS, 2006. 1 CD-ROM.

LANDIS, J.; KOCH, G. G. The measurements of observer agreement for categorical data. Biometrics, Washington, v. 33, n. 3, p. 159-179, 1977.

MARTINS, A. K. E. et al. Relações solo-geoambiente em áreas de ocorrência de Ipucas na planície do Médio Araguaia - Estado do Tocantins. Revista Árvore, Viçosa, v. 30, n. 2, p. 297-310, 2006.

MOURA FILHO, W.; BUOL, S. W. Studies of a Latossol Roxo (Eutrustox) in Brazil: micromorphology effect on ion release. Experientiae, Viçosa, v. 13, n. 7, p. 235-247, 1972.

MUGGLER, C. C. et al. Características pedológicas de ambientes agrícolas nos chapadões do Rio Corrente, sudeste da Bahia. Pesquisa Agropecuária Brasileira, Brasília, DF, v. 31, n. 3, p. 221-232, 1996.

OLIVEIRA, J. B. Pedologia aplicada. 2. ed. Piracicaba: Fealq, 2005.

OLIVEIRA, J. B.; JACOMINE, P. K. T.; CAMARGO, M. N. Classes gerais de solos do Brasil: guia auxiliar para o reconhecimento. Jaboticabal: Funep, 1992.

PREVEDELLO, C. L. Física do solo com problemas resolvidos. Curitiba: Salesward-discovery, 1996.
RAIJ, B. V. Fertilidade do solo e adubação. Piracicaba: Ceres, 1991.

RAMALHO FILHO, A.; BEEK, K. J. Sistema de avaliação da aptidão agrícola das terras. Rio de Janeiro: Embrapa/CNPS, 1995.

RESENDE, M.; LANI, J. L.; REZENDE, S. B. Pedossistemas da Mata Atlântica: considerações pertinentes sobre a sustentabilidade. Revista Árvore, Viçosa, v. 26, n. 3, p. 261-269, 2002.

RESENDE, M.; REZENDE, S. B. Levantamento de solos: uma estratificação de ambientes. Informe Agropecuário, Belo Horizonte, v. 9, n. 105, p. 3-25, 1983.

RESENDE, M. et al. Pedologia: base para distinção de ambientes. Lavras: UFLa, 2007.

RIBEIRO, J. F.; WALTER, B. M. T. Fitofisionomias do bioma Cerrado. In: SANO, S. M.; ALMEIDA, S. P. (Eds.). Cerrado: ambiente e flora. Planaltina: Embrapa Cerrados, 1998. p. 89-152.

SANTANA, H. M. P. Unidades pedoambientais da região de Santa Tereza, Estado do Tocantins. 2008. 132 f. Dissertação (Mestrado em Ciências Agrárias)Universidade de Brasília, Brasília, DF, 2008.

SANTOS, R. D. et al. Manual de descrição e coleta de solo no campo. Viçosa: Sociedade Brasileira de Ciência do Solo, 2005.

TOCANTINS. Secretaria de Planejamento e Meio Ambiente. Atlas do Tocantins: subsídios ao planejamento da gestão territorial. Palmas: Seplan, 2005.

VIEIRA, L. S. Manual de ciências do solo com ênfase aos solos tropicais. São Paulo: Agronômica Ceres, 1988. 